\title{
BMJ Open Social networks, leisure activities and maximum tongue pressure: cross- sectional associations in the Nagasaki Islands Study
}

\author{
Mako Nagayoshi, ${ }^{1}$ Miho Higashi, ${ }^{2}$ Noboru Takamura, ${ }^{2}$ Mami Tamai, ${ }^{3}$ \\ Jun Koyamatsu, ${ }^{4}$ Hirotomo Yamanashi, ${ }^{4}$ Koichiro Kadota, ${ }^{1}$ Shimpei Sato, ${ }^{1}$ \\ Shin-ya Kawashiri, ${ }^{1}$ Zenya Koyama, ${ }^{5}$ Toshiyuki Saito, ${ }^{5}$ Takahiro Maeda ${ }^{1,4}$
}

To cite: Nagayoshi M, Higashi M, Takamura N, et al. Social networks, leisure activities and maximum tongue pressure: cross-sectional associations in the Nagasaki Islands Study. BMJ Open 2017;7:e014878. doi:10.1136/ bmjopen-2016-014878

- Prepublication history and additional material for this paper are available online. To view these files, please visit the journal online (http://dx.doi. org/10.1136/bmjopen-2016014878).

Received 12 April 2017 Revised 8 September 2017 Accepted 3 October 2017

CrossMark

For numbered affiliations see end of article.

Correspondence to

Dr Mako Nagayoshi;

mnagayoshi@nagasaki-u.ac.jp

\section{ABSTRACT}

Objectives Social environment is often associated with health outcomes, but epidemiological evidence for its effect on oral frailty, a potential risk factor for aspiration, is sparse. This study aimed to assess the association between social environment and tongue pressure, as an important measure of oral function. The study focused on family structure, social networks both with and beyond neighbours, and participation in leisure activities.

Design A population-based cross-sectional study.

Setting Annual health check-ups in a rural community in Japan.

Participants A total of 1982 participants, all over 40 years old. Anyone with missing data for the main outcome $(n=14)$ was excluded.

Outcome measures Tongue pressure was measured three times, and the maximum tongue pressure was used for analysis. A multivariable adjusted regression model was used to calculate parameter estimates (B) for tongue pressure.

Results Having a social network involving neighbours $(B=2.43, P=0.0001)$ and taking part in leisure activities $(B=1.58, P=0.005)$ were independently associated with higher tongue pressure, but there was no link with social networks beyond neighbours $(B=0.23, P=0.77$ ). Sexspecific analyses showed that for men, having a partner was associated with higher tongue pressure, independent of the number of people in the household $(B=2.26$, $P=0.01)$, but there was no association among women $(B=-0.24, P=0.72 ; P$-interaction $=0.059)$.

Conclusions Having a social network involving neighbours and taking part in leisure activities were independently associated with higher tongue pressure. Marital status may be an important factor in higher tongue pressure in men.

\section{INTRODUCTION}

The proportion of people aged 60 years or over is expected to rise from $12 \%$ to $22 \%$ of the total global population between 2015 and 2050. ${ }^{1}$ In Japan, it was already $33 \%$ in 2015 and is still rising. ${ }^{2}$ Pneumonia is the third most common cause of death in Japan, ${ }^{2}$
Strengths and limitations of this study

- This is the first study of which we are aware to examine a possible association between tongue pressure and social environment among populationbased samples.

- Social environment was measured using a unique approach, focusing on family structure, social networks both with neighbours and beyond, and leisure activities, using simple questions.

- Detailed information about social networks and leisure activities, including quality and quantity of social networks, or type of activities, was not available.

- Social environment data were self-reported, and may therefore reflect a point in time, rather than a long-term situation.

- Causal relationships cannot be inferred because of the cross-sectional design.

and often results in reduced quality of life for both patients with pneumonia and their families, as well as high medical costs. ${ }^{23}$ The vast majority $(97 \%)$ of pneumonia deaths in Japan in 2015 were among those aged 65 years or over, ${ }^{2}$ and most cases hospitalised for pneumonia were aspiration pneumonia. ${ }^{4}$ Dysphagia is a main cause of aspiration, ${ }^{5}$ and a susceptible condition for development of pneumonia in older people. A recent systematic review of high-quality studies reported that estimated mean prevalence of dysphagia among community-dwelling older people is $15 \% .^{6}$ Dysphagia and related aspiration pneumonia prevention for both older people and younger populations is therefore a public health priority in Japan and is expected to be an important issue in other countries.

Social environment refers to the immediate physical surroundings, social relationships and cultural milieus within which defined groups of people function and interact, ${ }^{7}$ and 
which has a strong influence on physical and psychological health. 'Social network' is part of the social environment, covering the structure of relationships, both quality and quantity, ${ }^{9} 10$ including family relationships. For example, family members could have a strong influence on health ${ }^{11}$ through lifestyle factors such as diet, economic situation, living environment, behaviour or emotions. Having a small social network has been linked to higher risk of mortality ${ }^{12}$ and incidence of cardiovascular diseases (coronary heart disease, ${ }^{1214}$ heart failure ${ }^{15}$ and stroke $\mathrm{e}^{1013}$ ). Having fewer social interactions may be associated with earlier onset of physical and/or cognitive functional disability. ${ }^{16}$ Although some population-based studies have suggested that social relationships were associated with oral health, including number of teeth remaining, tooth decay and periodontitis, ${ }^{17} 18$ evidence of their effect on tongue pressure is sparse. Tongue pressure is essential to mix food and saliva into a bolus and pass it to the pharynx, which is an important phase in the feeding and swallowing process..$^{19}{ }^{20}$ The tongue also has important functions in daily activities and communications because tongue movement controls articulation and pronunciation. ${ }^{21}$

Lower oral function is related to dysphagia and subsequent aspiration pneumonia. ${ }^{22}$ Risk factors for dysphagia include age, existence of lung diseases, stroke, ${ }^{23}$ dementia, Parkinson's disease, low tongue pressure, tooth loss, diabetes or xerostomia, ${ }^{24}$ use of hypertension medication, antipsychotic drugs and malnutrition. ${ }^{6} \mathrm{Bad}$ oral health and poor oral hygiene have been linked to the development of aspiration pneumonia, ${ }^{24} 25$ and oral care has been reported as a preventive factor. ${ }^{25}$

Previous experimental studies have shown that lingual exercise $^{26}$ had a positive influence on tongue function assessed by isometric and swallowing pressures, and lingual volume. No study, however, has examined whether social environment and daily activities are associated with tongue pressure as a potential risk factor for dysphagia and aspiration. Dysphagia and risk of aspiration can be evaluated in a hospital, measuring swallowing function by videofluoroscopic examination and videoendoscopic evaluation of swallowing, but these techniques are not useful for screening in a community. Tongue pressure measurement has recently been identified as a useful proxy for risk of aspiration, ${ }^{27} 28$ as it assesses tongue motor function. Good reproducibility and high correlations of this measurement with other objective measurements for oral function (eg, the repetitive saliva swallowing test, speech intelligibility test, oral diadochokinesis and capacity of tongue-holding and movement test) ${ }^{21}$ and symptoms of dysphagia ${ }^{28}$ have been reported.

We hypothesised that social environment and daily activities may influence tongue pressure, because having social networks and taking part in leisure activities may increase opportunities to move the tongue. We also hypothesised that there may be sex differences in those associations because of possible biological sex differences ${ }^{29}$ and cultural gender roles in Japan, where men work outside the home, and women tend to be more involved in household chores. ${ }^{30}$ In such a culture, social environments could differ by sex. Using data from the Nagasaki Islands Study, we tested the hypotheses that people's social environment, including their family structure, social networks with and beyond their neighbours,and participation in leisure activities would be positively associated with higher tongue pressure, independent of physical, psychological and behavioural risk factors for dysphagia.

\section{METHODS \\ Study sample}

The Goto city municipal government provides annual health check-ups for all residents aged 40 years or older. These check-ups take place in community centres within walking distance of each person's home. The Nagasaki Islands Study collaborated with the local government to conduct research, mainly targeting atherosclerosis diseases and frailty, by providing additional examinations. ${ }^{31}$ In this study, every family unit in Tamanoura and Naru districts in 2015, and Tomie, Kishuku, Miiraku and Hisaka districts in 2016 was informed about the additional examinations by flyers before the study $(\mathrm{n}=11741)$. All 2103 residents who attended the annual health check-ups received an initial invitation to participate in the Nagasaki Islands Study (response rate $=17.9 \%$ ). Of the 2103 participants, 1982 ( 821 men and 1161 women) participated in this study (agreement rate $=94.2 \%$ ). The Nagasaki Islands Study included maximum tongue pressure measurements. For this cross-sectional analysis, we excluded participants without data on tongue pressure $(n=14)$, resulting in a final sample for analysis of 815 men and 1153 women (see online supplemental figure 1).

\section{Measures}

\section{Tongue pressure measurement}

The tongue pressure measurement device (JMS Co, TPM-01) was used during health check-ups to evaluate a part of qualitative oral function by measuring maximum tongue pressure. The TPM-01 is a newly developed handheld manometry device, using a small balloontype disposable oral probe with a plastic pipe, which is placed on the upper surface of the tongue. The TPM-01 is approved as the first medical device for tongue pressure measurement in Japan in $2010 .^{21}$ The measurements by the device were closely equivalent to those of the other widely used tongue pressure manometers, the Iowa Oral Performance Instrument, and the stable adhered three air-filled bulbs manometry system of the KayPENTAX Digital Swallowing Workstation. ${ }^{32}$ As a zero calibration, the probe was inflated with air at a pressure of $19.6 \mathrm{kPa}^{32}$ Measurement was performed in a relaxed sitting position, and participants were asked to compress the small balloon to the palate as hard as they could, using their tongue. The maximum value was recorded automatically and displayed on the device. ${ }^{32}$ The measurement was 
performed three times, and the maximum tongue pressure was used for analysis.

\section{Social environment assessment}

Social environment was assessed using a questionnaire about participants' social networks and daily activities. We asked about participants' family household structure, social networks with their neighbours and beyond, and participation in leisure activities. Family household structure was assessed by number of family members in the household, and marital status. Participants were asked whether they were married, divorced, separated or unmarried, and responses were classified dichotomously as married (having a partner) or not. Social networks were assessed by asking 'Do you have any close neighbors with whom you can talk?' (social network involving neighbours), and 'Do you have any close friends, family or relatives beyond your neighbors whom you visit and who visit you?' (social network beyond neighbours). Leisure activities were assessed by asking 'Do you have any hobbies, interests or leisure activities inside or outside your home?'. Choices for those questions were yes or no. Those three questions about social networks and leisure activities are part of the Frailty Index for Japanese older people. $^{33}$

\section{Measurement of covariates}

Questionnaires were used to obtain information on age, sex, smoking status (current, former or never), alcohol use (current, former or never), physical exercise, psychological distress, medical history and medication use. Physical activity was assessed by asking 'Have you been in the habit of doing exercise that makes you sweat lightly for over $30 \mathrm{~min}$ a time, at least twice weekly, for over a year?' and 'In your daily life, do you walk or do an equivalent amount of physical activity for more than one hour a day?'. The choices were yes or no. Participants who answered no for both questions were considered to be physically inactive, and those who answered yes for either as physically active.

Psychological distress was measured using the Japanese version of the Kessler 6 (K6) scale, a quantifier of non-specific psychological distress. ${ }^{34}$ Physiological variables were measured by trained technicians. Weight $(\mathrm{kg})$ and height $(\mathrm{cm})$ were measured in light clothes (DC-250; Tanita, Tokyo, Japan). Resting blood pressure was measured using digital devices (HEM-907; Omron, Kyoto, Japan). Hypertension was defined as diastolic blood pressure $\geq 90 \mathrm{~mm} \mathrm{Hg}$, systolic blood pressure $\geq 140 \mathrm{~mm} \mathrm{Hg}$ and/or self-reported antihypertensive medication use. Diabetes mellitus was defined as haemoglobin A1c $\geq 6.5 \%$, or use of medication for diabetes. History of stroke and respiratory disease was identified by self-reported medication use or having accessed medical care for those diseases. All measurements are routinely provided for all participants.

\section{Statistical analysis}

Descriptive statistics of covariates and potential mediators, by participants' sex, were generated using Student's t-tests and $\chi^{2}$ tests. To see sex-specific and age-specific distribution of maximum tongue strength and oral frailty, the proportions of each age group (40-49, 50-59, 60-69, 70-79 and 80 years or over) in each maximum tongue pressure band $(<19.9 \mathrm{kPa}, 20.0-29.9 \mathrm{kPa}, 30.0-39.9 \mathrm{kPa}$ and $\geq 40 \mathrm{kPa}$ ) were calculated. There is no validated cut-off point for maximum tongue pressure indicating oral frailty. ${ }^{20} 27$ Association between marital status and number of family members in the household was assessed by Wilcoxon rank-sum test. We used $\chi^{2}$ tests to examine whether there were links between marital status, social networks and leisure activity. Multiple linear regression analysis was used to calculate total and sex-specific parameter estimates (B) for maximum tongue pressure after sequential adjustment for potential confounding variables. We used four sequential models. Model 1 adjusted for age [continuous] and sex; model 2 also adjusted for body mass index [continuous], lifestyle factors (smoking status [categorical], alcohol drinking status [categorical] and physical activity [dichotomous]), psychological distress (K6 score [continuous]) and major risk factors for dysphagia (antihypertensive medicine use, diabetes and history of stroke and respiratory disease [all dichotomous]). The number of family members in the household, marital status, social networks with and beyond neighbours, and participation in leisure activities were included in the models. As marital status may be related to number of family members, we also included number of family members in the household (model 3) and marital status (model 4) separately to avoid overadjustment.

In sensitivity analyses, we excluded participants with a history of stroke or respiratory disease, to avoid the possibility that lower tongue pressure or overall oral function was an after-effect of those diseases. We also examined the sex-specific associations, and tested whether sex modified the relationships of social networks and leisure activities with maximum tongue pressure, by including crossproduct terms in the models (model 2). All analyses used SAS V.9.4.

\section{RESULTS}

The 1968 participants in our final sample for analysis were on average 70.6 years old (range $40-95$ ), $59 \%$ female and with a mean BMI of $23.4 \mathrm{~kg} / \mathrm{m}^{2}$. Table 1 shows the characteristics of participants by sex. The mean (SD) maximum tongue pressure was $32.4(10.4) \mathrm{kPa}$ in men and 29.8 (9.6) $\mathrm{kPa}$ in women ( $\mathrm{P}$ for difference $<0.0001)$. The tongue pressure was lower among older age groups in both men and women (figure 1). A total of $93(11.4 \%)$ men were classified as having a tongue pressure $<19.9 \mathrm{kPa}, 227$ $(27.9 \%)$ as 20.0 to $29.9 \mathrm{kPa}$, and $495(60.7 \%)$ as $\geq 30 \mathrm{kPa}$. In women, the figures were 171 (14.8\%), $384(33.3 \%)$ and $598(51.9 \%)$. The mean number of family members in the household was greater for men (2.2 people) than women 
Open Access

Table 1 Participant characteristics according to sex: the Nagasaki Islands Study 2015-2016

\begin{tabular}{|c|c|c|c|c|c|}
\hline \multirow{2}{*}{$\begin{array}{l}\text { Sex category } \\
\mathrm{N}\end{array}$} & \multirow{2}{*}{$\begin{array}{l}\text { Women } \\
1153\end{array}$} & \multirow{2}{*}{$\begin{array}{l}\text { Men } \\
815\end{array}$} & \multirow[t]{2}{*}{$\begin{array}{l}\mathrm{P} \text { for } \\
\text { difference }\end{array}$} & \multicolumn{2}{|c|}{$\begin{array}{l}\text { Average maximum tongue } \\
\text { pressure, } \mathrm{kPa}^{*}\end{array}$} \\
\hline & & & & Women & Men \\
\hline \multicolumn{6}{|l|}{ Demographics } \\
\hline Age, years* & $70.4 \pm 9.3$ & $70.1 \pm 10.3$ & 0.44 & - & - \\
\hline \multicolumn{6}{|c|}{ Lifestyle factors } \\
\hline \multicolumn{6}{|c|}{ Physical activity, n (\%) } \\
\hline Inactive & $162(14.1)$ & $146(17.9)$ & 0.02 & $30.0 \pm 9.0$ & $32.2 \pm 11.0$ \\
\hline Active & 991 (85.9) & $669(82.1)$ & & $29.8 \pm 9.7$ & $32.5 \pm 10.3$ \\
\hline \multicolumn{6}{|c|}{ Cigarette smoking status, $\mathrm{n}(\%)$} \\
\hline Never & $1084(94.0)$ & $220(27.0)$ & $<0.0001$ & $29.7 \pm 9.7$ & $29.9 \pm 10.4$ \\
\hline Former & $44(3.8)$ & $428(20.5)$ & & $32.1 \pm 10.2$ & $32.7 \pm 10.5$ \\
\hline Current & $25(2.2)$ & $167(52.5)$ & & $32.0 \pm 7.1$ & $35.1 \pm 9.7$ \\
\hline \multicolumn{6}{|c|}{ Alcohol drinking status, n (\%) } \\
\hline Never & 910 (78.9) & $230(28.2)$ & $<0.0001$ & $29.3 \pm 9.9$ & $31.0 \pm 10.1$ \\
\hline Former & $29(2.5)$ & $93(11.4)$ & & $30.5 \pm 9.7$ & $28.1 \pm 11.0$ \\
\hline Current & $214(18.6)$ & $492(60.4)$ & & $32.0 \pm 8.1$ & $33.9 \pm 10.2$ \\
\hline
\end{tabular}

Physiological characteristics

Maximum tongue pressure

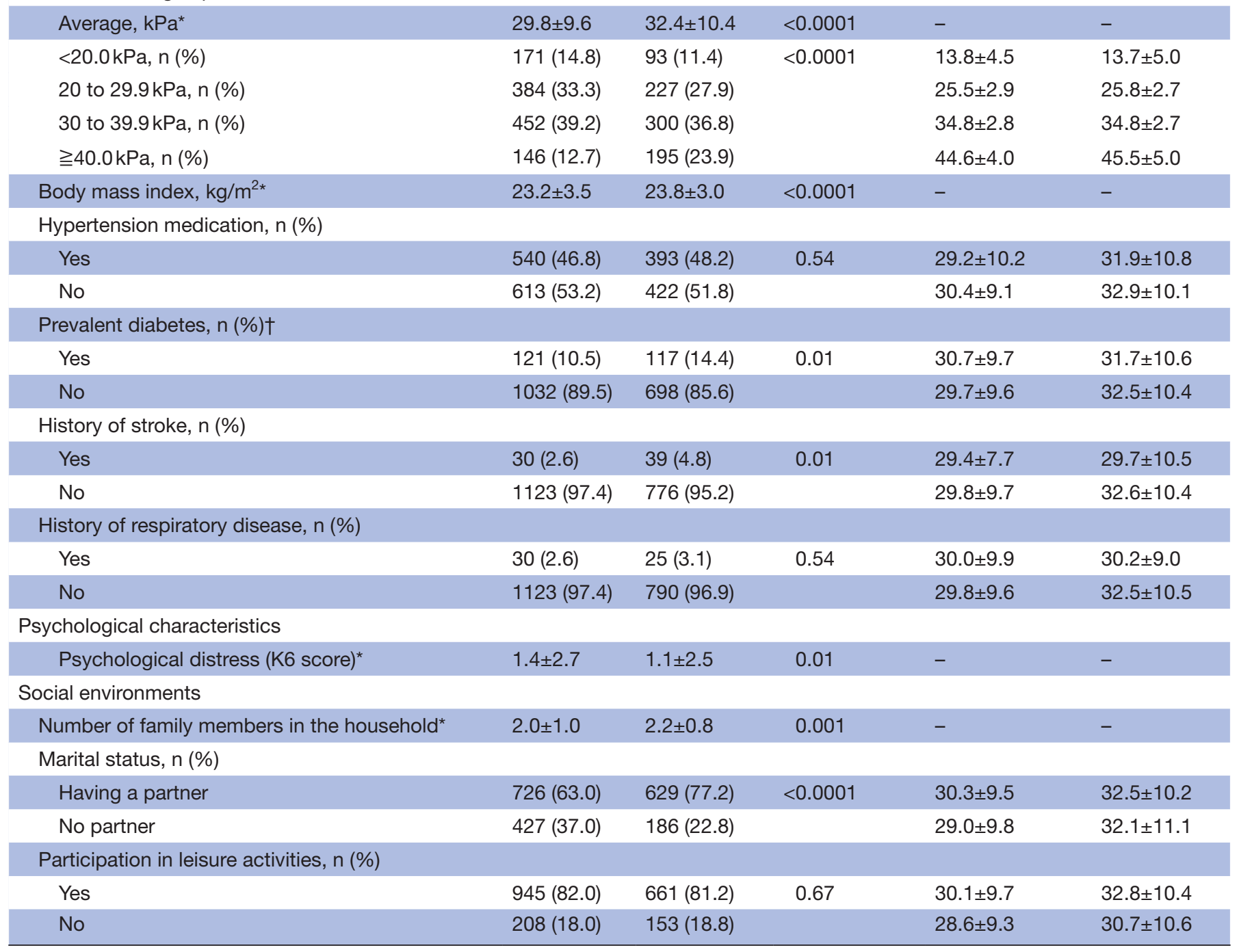




\begin{tabular}{|c|c|c|c|c|c|}
\hline $\begin{array}{l}\text { Sex category } \\
\mathrm{N}\end{array}$ & $\begin{array}{l}\text { Women } \\
1153\end{array}$ & $\begin{array}{l}\text { Men } \\
815\end{array}$ & $\begin{array}{l}\text { P for } \\
\text { difference }\end{array}$ & \multicolumn{2}{|c|}{$\begin{array}{l}\text { Average maximum tongue } \\
\text { pressure, } \mathrm{kPa}^{*}\end{array}$} \\
\hline \multicolumn{6}{|c|}{ Having a social network with neighbours, $n(\%)$} \\
\hline Yes & $1001(86.8)$ & $660(81.0)$ & 0.0004 & $30.2 \pm 9.4$ & $33.0 \pm 10.3$ \\
\hline Yes & 1062 (92.1) & $724(88.8)$ & 0.01 & $30.0 \pm 9.6$ & $32.7 \pm 10.4$ \\
\hline No & 91 (7.9) & $91(11.2)$ & & $28.2 \pm 9.9$ & $30.4 \pm 10.3$ \\
\hline
\end{tabular}

${ }^{*}$ Represented as mean \pm SD.

†Diabetes was defined as haemoglobin $\mathrm{A} 1 \mathrm{c} \geq 6.5 \%$, or medication use for diabetes.

(2.0 people) $(\mathrm{P}=0.001)$. The proportion of men having a partner was also higher $(77 \%$ vs $63 \%)(\mathrm{P}<0.0001)$.

\section{Social environment and maximum tongue pressure among participants}

Multivariable adjusted linear regression analysis showed that having a social network involving neighbours and participation in leisure activities were positively associated with higher tongue pressure. The multivariable adjusted parameter estimates $(\mathrm{B})$ were $2.43(\mathrm{P}=0.0001)$ and 1.58 $(\mathrm{P}=0.005)$ (table 2, model 2). The number of family members in the household, marital status and having a social network beyond neighbours were not associated with maximum tongue pressure. The associations did not change when we included number of family members in the household (model 3) and marital status (model 4) separately.

Using Wilcoxon rank-sum test, the number of family members in the household was larger for participants with a partner than those without $(\mathrm{P}<0.0001)$. The average number of family members living in the household was $2.08 \pm 0.93$, and $87 \%$ of participants who were living with someone were married. Using $\chi^{2}$ tests, marital status (having a partner) was associated with taking part in leisure activities and having social networks with/ beyond neighbours in men (all $\mathrm{P}<0.0001$ ), but not in women. Having social networks with neighbours was associated with taking part in leisure activities and having social networks beyond neighbours in both men and women. Having social networks with/beyond neighbours was also associated with taking part in leisure activities in both sexes.

\section{Sex-specific association in social environment and maximum} tongue pressure

In the sex-specific multivariable adjusted linear regression analyses, the associations between maximum tongue pressure and either social networks involving neighbours

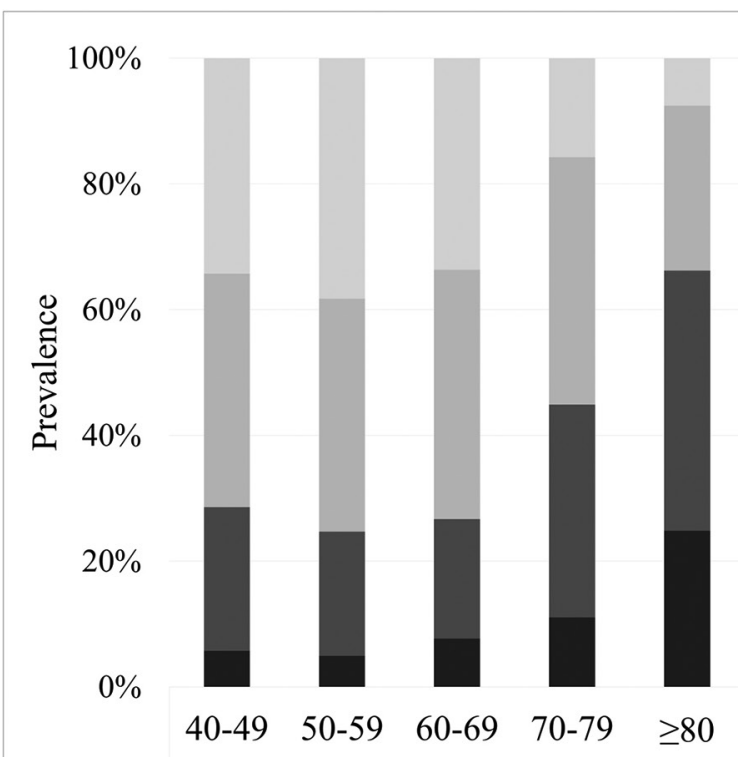

Men

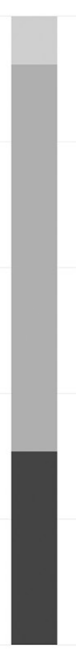

$40-49$

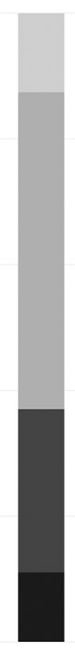

50-59
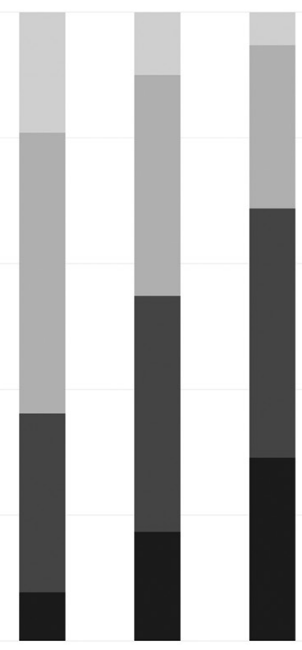

$60-69 \quad 70-79 \geq 80$

Figure 1 Sex-specific maximum tongue pressure by age group: the Nagasaki Islands Study 2015-2016. 


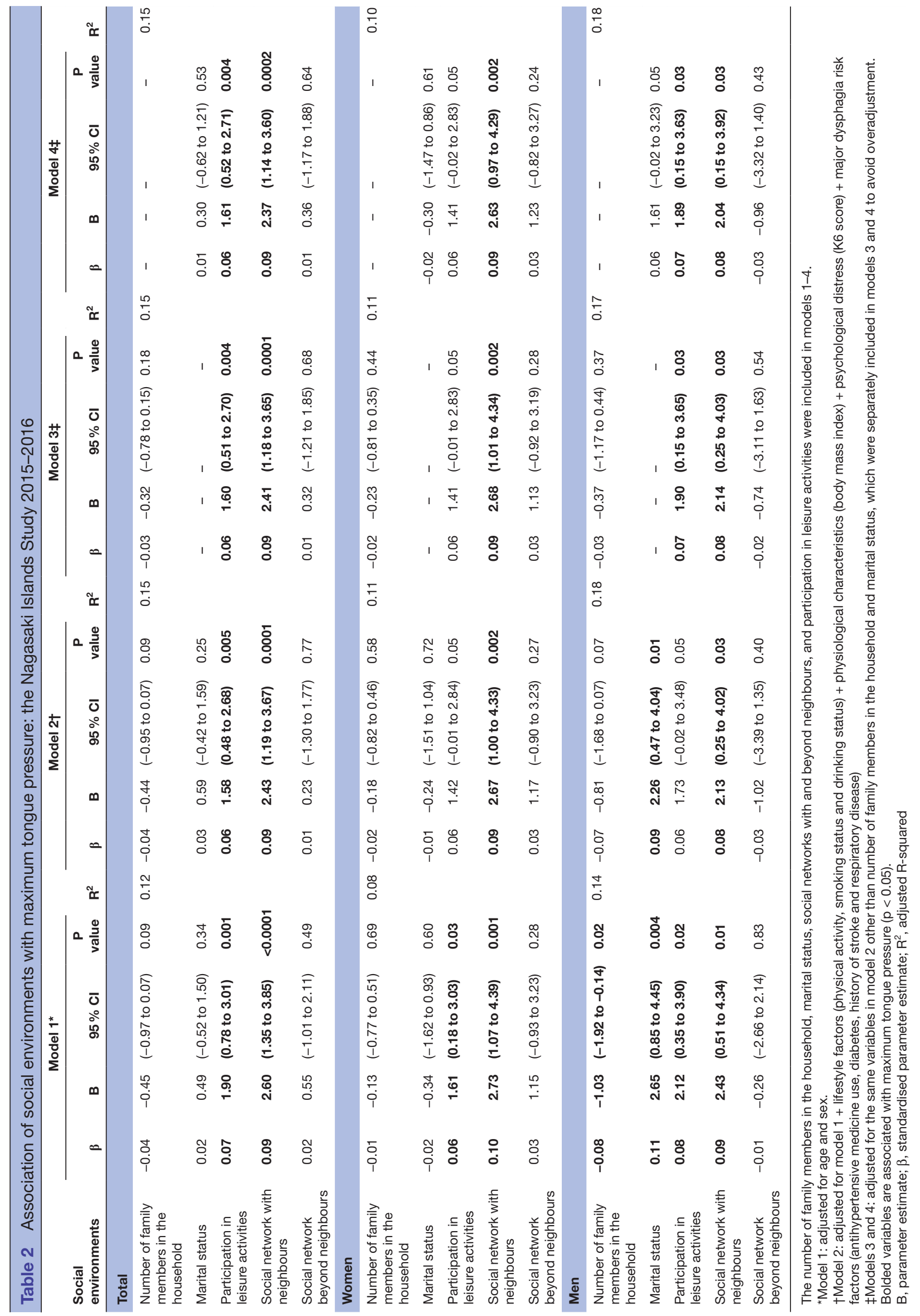


or participation in leisure activities were similar to the combined figures for women and men. The multivariable adjusted $\mathrm{B}$-values were $2.67(\mathrm{P}=0.002)$ and $1.42(\mathrm{P}=0.05)$ for women, and $2.13(\mathrm{P}=0.03)$ and $1.73(\mathrm{P}=0.05)$ for men (table 2, model 2). Having social networks beyond neighbours was not associated with tongue pressure at all, whereas number of family members in the household tended to be negatively associated $(\mathrm{B}=-0.81, \mathrm{P}=0.07)$, and marital status (having a partner) was significantly positively associated with higher tongue pressure in men $(\mathrm{B}=2.26, \mathrm{P}=0.01)$, but not women $(\mathrm{B}=-0.18, \mathrm{P}=0.58$, and $\mathrm{B}=-0.24, \mathrm{P}=0.72)$. When we separately included number of family members in the household (model 3) and marital status (model 4), the associations were attenuated in men, but the attenuation did not alter the relationships of social networks and participation in leisure activities with tongue pressure.

In sensitivity analyses excluding participants with stroke or respiratory disease to exclude influences on tongue pressure or overall oral function from those diseases or associated medication, neither the overall nor sex-specific results changed (online supplemental table 1). There was no evidence that sex modified the relationship of number of family members in the household, networks with and beyond neighbours, and leisure activities with maximum tongue pressure (interaction $\mathrm{P}=0.87, \mathrm{P}=0.36, \mathrm{P}=0.19$ and $\mathrm{P}=1.00$ ). It did, however, show a borderline significant interaction in the association between marital status and maximum tongue pressure (interaction $\mathrm{P}=0.059$ ).

\section{DISCUSSION}

In this population-based study of 1968 participants, having a social network involving neighbours and participating in leisure activities were associated with higher maximum tongue pressure. This association was independent of age, sex, body mass index, psychological distress, behavioural factors and other risk factors for dysphagia. Having a partner was associated with greater tongue pressure in men only. This is the first evidence of which we are aware that suggests that social environment may influence tongue pressure. It supports previous reports suggesting the importance of social ties and taking part in daily leisure activities in improving or maintaining tongue function and possible prevention of dysphagia and aspiration.

Our results are consistent with previous studies on daily and social activities, in which oral function was assessed by self-reported questionnaire. ${ }^{356}$ Kamakura et al carried out a questionnaire survey among 769 local senior club members, and reported that factors related to daily activities such as time spent outside the home each day, higher frequency of loud laughing and enjoying eating were associated with a lower proportion of swallowing problems (self-reported choking on food). ${ }^{35}$ A previous community-based study of 1405 randomly selected older people showed that not participating in social activities was linked to a self-assessed masticatory problem. ${ }^{37}$
Although the mechanisms underlying the association between social networks or participation in leisure activities and tongue pressure have not been fully elucidated, physiological, behavioural and psychological factors are likely to be involved. Higher activity in muscles around the pharynx and mouth may have a positive effect on tongue function. People who are living with family members and have close neighbours may communicate with others more often, and particularly have more opportunity to eat together, have conversations and laugh. Eating with someone could have a positive influence on oral function via increased saliva production and higher tongue activity, as well as having a preventive effect on depression. ${ }^{38}$ It may also be related to better nutrition, eating behaviour, dietary composition and energy levels, ${ }^{39}$ as well as more social interactions. ${ }^{40} \mathrm{~A}$ link was identified between laughter and enjoying eating and lower self-reported symptoms of aspiration in an epidemiological study. ${ }^{35}$

The difference in frequency of social interactions in daily life could explain why only social networks involving neighbours, and not those beyond, were associated with higher tongue pressure in this study. The influence of social networks beyond neighbours on tongue pressure could depend on both the type of relationship (close family, wider relatives or friends) and frequency of meeting, but the results suggest a possibility that an effective public health intervention to prevent oral frailty and subsequent aspiration might focus on social networks involving neighbours. Hikichi et al reported that community intervention may be effective in encouraging social participation among Japanese older people, and helping to prevent the onset of functional disability. ${ }^{16}$ That study confirmed that the number of community-based centres for older people, the so-called 'community salons', within $350 \mathrm{~m}$ of the home was related to frequency of participation. It also found that incidence of functional disability among residents who participated in community salons three or more times over the 4.9 years of follow-up was reduced by $50 \%$ over those who participated twice or less. The result was similar even when the researchers accounted for the possibility of selection bias by using propensity score matching analysis and instrumental variable analysis. ${ }^{16}$

The number of family members in the household was not associated with tongue pressure in the combined analysis, and a negative association was observed in men. We think that this may be partially because of possible differences in duration of living with family members. There is also a possibility of reverse causation: some people may have started to live with family members as a result of decreased ability to perform activities of daily living. We did not collect any detailed information about leisure activities, but these could be related to higher social interaction, physical/mental activity, self-actualisation or 'Ikigai', a comprehensive Japanese concept encompassing the 'meaning of life' and/or 'purpose in life'. ${ }^{41}$ Large population-based longitudinal studies of older people in 
Japan have reported that having hobbies or social participation may be effective in decreasing the risk of functional disability, ${ }^{42}$ and progression of senility associated with dementia. ${ }^{43}$ A previous report from the Japanese government showed that people with more friends had a stronger feeling of Ikigai. ${ }^{36}$ The proportion participating in leisure activities was higher in participants with social networks both with and beyond neighbours in our study, but we believe the associations with higher tongue pressure are likely to be independent. The reason for the sex difference in the association between marital status and tongue pressure is unknown, but cultural gender roles in Japan and health-related behaviours could partially mediate the association. As men more often work outside the home, and women are more involved in household chores in Japan, ${ }^{30}$ women may have more opportunity to communicate with their neighbours than men, regardless of marital status. Our results suggested that the proportion having social networks and participating in leisure activities were higher among married men than unmarried. Health-compromising behaviours (eg, smoking, heavy drinking, lower vegetable consumption and less frequent dental visits) have previously been shown to be related to marital status in both men ${ }^{44}$ and women. ${ }^{45} 46$ Marital termination (eg, divorce and widowhood) was associated with an elevated mortality risk for men, but not for women in a large Japanese cohort study. ${ }^{47}$

The association between tongue pressure and both social networks and participation in leisure activities was independent of psychological distress in this study. Psychological distress could influence oral function via lower frequency and number of communications, related to reduced social interaction, ${ }^{48}$ as well as altered health-promoting behaviours (eg, brushing teeth, consuming a healthy diet, exercising and not smoking). Medication use for depression is also known to be a risk factor for dysphagia and aspiration because of the muscle relaxant effect. A future study examining links with medication use for depression may be helpful.

\section{Strengths and limitations}

Our study had several limitations. Social networks and participation in leisure activities were assessed using a dichotomous answer, so detailed information about the social network quality (eg, relationship or closeness) and quantity (eg, number involved in the social network, and frequency of communications), or the type of activity (eg, solo or social activity) were not available in this study. However, the simplicity of the question is useful in identifying people with at least one social network or leisure activity. Further studies will be needed to investigate the influence of various detailed aspects of social networks and leisure activities on tongue pressure. Second, measurement error and subsequent misclassification almost certainly occurred, because the social environment data were self-reported. Participants' answers were about their mental and social environment at the point of response, and further studies will therefore be needed to assess the duration of the situation (eg, how long they have been living alone) and timing (eg, when they lost their partner or retired). Third, tongue pressure measurement has good reproducibility and high correlations with other objective measurements for oral functions, ${ }^{21}$ but unmeasured characteristics of the participants like cognitive decline, or oral conditions like denture use could have influenced the measurement. Fourth, although we adjusted for potential confounders including disease-related dysphagia risk (stroke, and respiratory disease), there may have been other residual or unmeasured confounders (for example, other diseases like dementia, epilepsy, medication use including anticholinergics, diuretics, antidepressant or sleep medicine, and diet and lifestyle changes) that influenced the association between social environment and tongue pressure. Fifth, causal relationships cannot be identified from cross-sectional analyses. There is a possibility of reverse causation or bidirectional relationships. ${ }^{49}$ For example, people without oral frailty may maintain larger social networks or participate in more daily activities, or some people could have started to live with family members as a result of weakened physical function, but this cannot be assessed. Sixth, the study response rate was under $20 \%$ in the target population in the city, which may have led to selection bias. However, we believe that the high rate of agreement to participate $(94 \%)$ is likely to have minimised any bias among the population. Seventh, although age-related social environment differences and/or tongue pressure (figure 1) may have influenced the associations, we could not assess the most appropriate age cut-off point for the associations, partly because we have limited population data to explore this. Further research with a larger sample sizes or prospective design would be needed to investigate whether there are age-specific associations. Last, our study subjects were from a rural area in Japan, in which social ties with neighbours could be stronger than those in urban areas. Further research would be needed to assess the generalisability of the study.

The strengths of our study included objective measurement of tongue pressure using population-based samples, a comprehensive assessment of social environment focusing on family structure, social networks within and beyond neighbours, and participation in leisure activities, and standardised data collection for potential risk factors for dysphagia including psychological distress, and physical and behavioural characteristics.

\section{CONCLUSIONS}

Having a social network involving neighbours and taking part in leisure activities were independently associated with higher maximum tongue pressure in a sample of community-dwelling men and women. Marital status may be also an important factor in maintaining tongue pressure among men. Further studies will be needed to assess the impact of particular elements of the social environment on tongue pressure, including social network size, 
quality and duration of the situation or type of activities, using a prospective design. This study, however, suggests the importance of family structure including marital status, social networks with and beyond neighbours, and participation in leisure activities for risk assessment of oral frailty.

\section{Author affiliations}

${ }^{1}$ Department of Community Medicine, Nagasaki University Graduate School of Biomedical Sciences, Nagasaki, Japan

${ }^{2}$ Department of Global Health, Medicine and Welfare, Atomic Bomb Disease Institute, Nagasaki University, Nagasaki, Japan

${ }^{3}$ Department of Immunology and Rheumatology, Nagasaki University Graduate School of Biomedical Sciences, Nagasaki, Japan

${ }^{4}$ Department of Island and Community Medicine, Nagasaki University Graduate School of Biomedical Sciences, Nagasaki, Japan

${ }^{5}$ Department of Oral Health, Nagasaki University Graduate School of Biomedical Sciences, Nagasaki, Japan

Acknowledgements The authors thank the staff and participants of the Nagasaki Islands Study for their important contributions, and staff members from the office of the divisions of healthpolicy and long-term care in Goto city for their collaboration. We thank Edanz Group (www.edanzediting.com/ac) for editing a draft of this manuscript.

Contributors MN conceived the study, analysed and interpreted the data, drafted the manuscript, and provided statistical expertise. MN, MH, NT, MT, JK, HY, KK, SS, ZK, TS and TM acquired the data. MN, MH, NT, MT, JK, HY, KK, SS, S-yK, ZK, TS and TM interpreted the data and critically revised the manuscript. TM is guarantor for the study. All authors approved the final version of the paper.

Funding This work was supported by Grants-in-Aid for Scientific Research (no. 17H03740) and by Grant-in-Aid for Young Scientists (A) (no. 16H06240) from the Japan Society for the Promotion of Science.

Competing interests None declared.

Ethics approval This study was approved by the Ethics Committee in Nagasaki University Graduate School of Biomedical Sciences (project registration no 14051404).

\section{Provenance and peer review Not commissioned; externally peer reviewed.}

Data sharing statement Researchers can apply for data by submitting a proposal to ritouken@vc.fctv-net.jp. After agreement of the proposed analysis by the steering committee, and approval by the executive committee, collaborative researchers receive participants' data based on the proposed analysis.

Open Access This is an Open Access article distributed in accordance with the Creative Commons Attribution Non Commercial (CC BY-NC 4.0) license, which permits others to distribute, remix, adapt, build upon this work non-commercially, and license their derivative works on different terms, provided the original work is properly cited and the use is non-commercial. See: http://creativecommons.org/ licenses/by-nc/4.0/

(c) Article author(s) (or their employer(s) unless otherwise stated in the text of the article) 2017. All rights reserved. No commercial use is permitted unless otherwise expressly granted.

\section{REFERENCES}

1. World Health Organisation. 10 facts on ageing and the life course. 2015 http://www.who.int/features/factfiles/ageing/ageing_facts/en/.

2. Health, Labour and Welfare Statistics Association. 2016. Journal of Health and Welfare Statistics 2016-2017 (in Japanese). Tokyo, Japan: Health, Labour and Welfare Statistics Association. 63 (9).

3. Michiwaki Y, Sumi Y. Estimated national health care costs for aspiration pneumonia over 70 Years Old Inpatients. Ronen Shika Igaku 2014;28:366-8.

4. Teramoto S, Fukuchi Y, Sasaki H, et al. High incidence of aspiration pneumonia in community- and hospital-acquired pneumonia in hospitalized patients: a multicenter, prospective study in Japan. J Am Geriatr Soc 2008;56:577-9.

5. Sue Eisenstadt E. Dysphagia and aspiration pneumonia in older adults. J Am Acad Nurse Pract 2010;22:17-22.
6. Madhavan A, LaGorio LA, Crary MA, et al. Prevalence of and risk factors for dysphagia in the community dwelling elderly: a systematic review. J Nutr Health Aging 2016;20:806-15.

7. Barnett E, Casper M. A definition of "social environment". Am J Public Health 2001;91:465.

8. Everson-Rose SA, Lewis TT. Psychosocial factors and cardiovascular diseases. Annu Rev Public Health 2005;26:469-500.

9. Arthur HM. Depression, isolation, social support, and cardiovascular disease in older adults. J Cardiovasc Nurs 2006;21:S2-7.

10. Nagayoshi M, Everson-Rose SA, Iso H, et al. Social network, social support, and risk of incident stroke: atherosclerosis risk in communities study. Stroke 2014:45:2868-73.

11. Ikeda $\mathrm{A}$, Iso $\mathrm{H}$, Kawachi I, et al. Living arrangement and coronary heart disease: the JPHC study. Heart 2009;95:577-83.

12. Eng PM, Rimm EB, Fitzmaurice G, et al. Social ties and change in social ties in relation to subsequent total and cause-specific mortality and coronary heart disease incidence in men. Am J Epidemiol 2002;155:700-9.

13. Kawachi I, Colditz GA, Ascherio A, et al. A prospective study of social networks in relation to total mortality and cardiovascular disease in men in the USA. J Epidemiol Community Health 1996;50:245-51.

14. Hemingway H, Marmot M. Evidence based cardiology: psychosocial factors in the aetiology and prognosis of coronary heart disease. Systematic review of prospective cohort studies. BMJ 1999;318:1460-7.

15. Cené CW, Loehr L, Lin FC, et al. Social isolation, vital exhaustion, and incident heart failure: findings from the Atherosclerosis Risk in Communities Study. Eur J Heart Fail 2012;14:748-53.

16. Hikichi $\mathrm{H}$, Kondo N, Kondo $\mathrm{K}$, et al. Effect of a community intervention programme promoting social interactions on functional disability prevention for older adults: propensity score matching and instrumental variable analyses, JAGES Taketoyo study. J Epidemiol Community Health 2015;69:905-10.

17. Tsakos G, Sabbah W, Chandola T, et al. Social relationships and oral health among adults aged 60 years or older. Psychosom Med 2013;75:178-86.

18. Merchant AT, Pitiphat W, Ahmed B, et al. A prospective study of social support, anger expression and risk of periodontitis in men. J Am Dent Assoc 2003;134:1591-6.

19. Leopold NA, Kagel MC. Swallowing, ingestion and dysphagia: a reappraisal. Arch Phys Med Rehabil 1983;64:371-3.

20. Utanohara $Y$, Hayashi R, Yoshikawa M, et al. Standard values of maximum tongue pressure taken using newly developed disposable tongue pressure measurement device. Dysphagia 2008;23:286-90.

21. Takeuchi K, Ozawa $\mathrm{Y}$, Hasegawa J, et al. Usability of maximum tongue pressure measurement in patients with dysphagia or dysarthria: using a newly developed measurement device. Japanese J Dysphagia Rehabil 2012;16:165-74.

22. van der Maarel-Wierink CD, Vanobbergen JN, Bronkhorst EM, et al. Risk factors for aspiration pneumonia in frail older people: a systematic literature review. J Am Med Dir Assoc 2011;12:344-54.

23. Adams HP, del Zoppo G, Alberts MJ, et al. Guidelines for the early management of adults with ischemic stroke. Circulation 2007;115:e478-534.

24. Prasse JE, Kikano GE. An overview of dysphagia in the elderly. Adv Stud Med 2004;4:527-33.

25. Yoneyama T, Yoshida M, Matsui T, et al. Oral care and pneumonia. The Lancet 1999;354:515.

26. Robbins J, Gangnon RE, Theis SM, et al. The effects of lingual exercise on swallowing in older adults. J Am Geriatr Soc 2005;53:1483-9.

27. Tsuga K. Maximum voluntary tongue pressure measurement with a disposable intra-oral probe and handy manometric device (In Japanese). Japanese Soc Stomatognathic Funct 2010:41-4.

28. Yoshida M, Kikutani T, Tsuga K, et al. Decreased tongue pressure reflects symptom of dysphagia. Dysphagia 2006;21:61-5.

29. Crow HC, Ship JA. Tongue strength and endurance in different aged individuals. J Gerontol A Biol Sci Med Sci 1996;51:M247-50.

30. Hachisuka K, Tsutsui Y, Furusawa K, et al. Gender differences in disability and lifestyle among community-dwelling elderly stroke patients in Kitakyushu, Japan. Arch Phys Med Rehabil 1998:79:998-1002.

31. Yamanashi H, Shimizu Y, Koyamatsu J, et al. Multiple somatic symptoms and frailty: cross-sectional study in Japanese communitydwelling elderly people. Fam Pract 2016;33:453-60.

32. Yoshikawa M, Yoshida M, Tsuga K, et al. Comparison of three types of tongue pressure measurement devices. Dysphagia 2011;26:232-7.

33. Shinkai $\mathrm{S}$, Watanabe $\mathrm{N}$, Yoshida $\mathrm{H}$, et al. Validity of the 'Kaigo-Yobo Check-List' as a frailty index. (In Japanese). Nihon Koshu Eisei Zasshi 2013:60:262-74. 
34. Furukawa TA, Kawakami N, Saitoh M, et al. The performance of the Japanese version of the K6 and K10 in the World Mental Health Survey Japan. Int J Methods Psychiatr Res 2008;17:152-8.

35. Kamakura Y, Okamoto K, Sugimoto S. Swallowing and Its correlates in the aged living at home. Sogo Rehabil 1998;26:581-7.

36. Cabinet Office $\mathrm{G}$ of $\mathrm{J}$. Koreisya no chiikishakai eno sanka ni kansuru Ishikichosa (Abstract of a report). 2009. 1-29 http://www8.cao.go.jp/ kourei/ishiki/h20/sougou/gaiyo/pdf/kekka.pdf.

37. Nakanishi N, Hino Y, Ida O, et al. Associations between selfassessed masticatory disability and health of community-residing elderly people. Community Dent Oral Epidemiol 1999;27:366-71.

38. Tani Y, Sasaki Y, Haseda M, et al. Eating alone and depression in older men and women by cohabitation status: the JAGES longitudinal survey. Age Ageing 2015;44:1019-26.

39. Cruwys T, Bevelander KE, Hermans RC. Social modeling of eating: a review of when and why social influence affects food intake and choice. Appetite 2015;86:3-18.

40. Vesnaver E, Keller HH. Social influences and eating behavior in later life: a review. J Nutr Gerontol Geriatr 2011;30:2-23.

41. Hasegawa A, Fujiwara Y, Hoshi T, et al. [Regional differences in ikigai (reason(s) for living) in elderly people--relationship between ikigai and family structure, physiological situation and functional capacity (In Japanese)]. Nihon Ronen Igakkai Zasshi 2003;40:390-6.
42. Kanamori S, Kai Y, Aida J, et al. Social participation and the prevention of functional disability in older Japanese: the JAGES cohort study. PLoS One 2014;9:e99638.

43. Takeda T, Kondo K, Hirai H. [Psychosocial risk factors involved in progressive dementia-associated senility among the elderly residing at home. AGES project--three year cohort longitudinal study (In Japanese)]. Nihon Koshu Eisei Zasshi 2010;57:1054-65.

44. Eng PM, Kawachi I, Fitzmaurice G, et al. Effects of marital transitions on changes in dietary and other health behaviours in US male health professionals. J Epidemiol Community Health 2005;59:56-62.

45. Watt RG, Heilmann A, Sabbah W, et al. Social relationships and health related behaviors among older US adults. BMC Public Health 2014;14:533.

46. Lee S, Cho E, Grodstein F, et al. Effects of marital transitions on changes in dietary and other health behaviours in US women. Int $J$ Epidemiol 2005;34:69-78.

47. Ikeda $\mathrm{A}$, Iso $\mathrm{H}$, Toyoshima $\mathrm{H}$, et al. Marital status and mortality among Japanese men and women: the Japan Collaborative Cohort Study. BMC Public Health 2007;7:73.

48. Schwarzbach M, Luppa M, Forstmeier S, et al. Social relations and depression in late life-a systematic review. Int $J$ Geriatr Psychiatry 2014;29:1-21.

49. Koyama S, Aida J, Kondo K, et al. Does poor dental health predict becoming homebound among older Japanese? BMC Oral Health 2016;16:51. 